\title{
Dynamics of the IgG3 responses following immunisation of BALB/c mice with somatic and excretory/secretory antigens from various Trichinella species
}

\author{
Maria Auxiliadora Dea-Ayuela and Francisco Bolas-Fernández
}

Departamento de Parasitologia, Facultad de Farmacia, Universidad Complutense, 28040-Madrid, Spain

Key words: Trichinella species, antigens, immunisation, IgG3

\begin{abstract}
Comparison of the dynamics and antigen recognition profiles of $\operatorname{IgG} 3$ following immunisation with larval crude extracts (LCE) and excretory-secretory (ES) products from muscle larvae of different species of Trichinella (T. spiralis, T. nativa, T. britovi, T. nelsoni and genotype T6) was made in BALB/c mice. High levels of IgG3 response were obtained in ELISA following immunisation with LCE from all species with maximum levels achieved between days 59 and 64 post-immunisation (p.i.) and maintained up to the limit of the observation (day 164). Antigen recognition profiles as measured by western-blot showed dense and numerous bands in the range $45-64 \mathrm{kDa}$ that were consistent from week $5^{\text {th }}$ with variation in epitope recognition among the different species. Following immunisation with ES antigens a significant decrease in IgG3 response was observed for all species especially for T. nativa in comparison to LCE. Antigen recognition on ES antigens showed three main bands in the range of 45-60 kDa for all species excepting T. nelsoni and T. britovi where an additional band was also present. These results clearly show that IgG3 epitopes are more abundant in somatic (LCE) than in ES products of Trichinella muscle larvae and that quantitative as well as qualitative variations exist among different species.
\end{abstract}

Chronic infections by Trichinella are due to the survival of the L1 stage inside a nurse cell surrounded by a cyst within the striated muscle fibres (Despommier 1975). Before this stage is reached an acute process occurs involving the intestine and circulatory systems that induces strong cellular and humoral immune responses (Wakelin 1993). Specific antibodies are measurable about two weeks after infection and can last for long time over all depending on the host species and the intensity of infection (Crandall and Crandall 1972, Ottesen et al. 1975).

Following Trichinella spiralis infections a two-phase humoral response is induced by two groups of antigens defined as group I (G-I) and II (G-II), as shown in mice by Denkers et al. (1990a, b). Antibodies against G-I reach maximum levels on day 13 p.i. and may be involved in effective responses against intestinal infection whereas those against G-II appeared between days 27 and 35 p.i.; they are mainly of the $\operatorname{IgG} 1$ and IgM class and are protective against re-infections. On the other hand, following infection of rats by $T$. spiralis it was shown that antibodies against excretory-secretory (ES) antigens (slow responders) appear after four weeks of infection and last for a long period of time (32 weeks) whereas those against somatic components (rapid responders), appear after two weeks and last for about 8 weeks (Takahashi et al. 1990).

Correlation between antibody responses and protection have been established by passive transfer experiments following immunisation by L1 extracts (Robinson et al. 1995a) or by protection against secondary infections either in rats (Wakelin and Denham 1983, Appleton and McGregor 1984, Bell 1992a) or in mice (Bell 1992b). Among isotypes the IgG1 subclass appears to play the most important role in protective responses (Appleton and McGregor 1987, Robinson et al. 1995b). IgG isotype responses have been widely investigated in both experimental and clinical trichinellosis, mainly involving the acute stage of infections by T. spiralis (Almond and Parkhouse 1986, Ljungstrom et al. 1988, Zakroff et al. 1989, Robinson et al. 1994) although few studies concerned the IgG3 subclass. IgG3 subclass isotype responses are related to carbohydrate epitopes (Snapper et al. 1992). It has been shown that certain thymusindependent antigens can induce the $\mathrm{CD}^{+} \mathrm{B}$ cell population to undergo an IgG3 class switch (Drabek et al. 1997). In mice, IgG3 subclass antibodies predominate in humoral responses to bacterial polysaccharide antigens with enhanced binding capacity to $\mathrm{N}$-acetylglucosamine (GlcNAc) residues (Greenspan and Cooper 1992). In Trichinella spiralis, a high proportion of GlcNAc and GalNAc was also found in the TSL-1 antigens (Wisnewski et al. 1993) and therefore this could be related with high levels of IgG3 response measured in the chronic stage of $T$. spiralis infections (personal observations).

Carbohydrate structures play important roles in the survival strategies of parasites such as Schistosoma spp. (Dunne et al. 1990) or Trypanosoma brucei (Ferguson et al. 1988). In Trichinella species relevant glycans 
bound to proteins of TSL-1 antigens have been identified (Denkers et al. 1991, Ellis et al. 1994, Romaris et al. unpublished results) that may be involved in muscle invasion and nurse cell development.

Therefore, in the present paper the dynamics of the IgG3 response following immunisation of BALB/c mice with somatic and ES products from L1 larvae of various species of Trichinella is compared towards further characterisation of IgG3 epitopes.

\section{MATERIALS AND METHODS}

Parasites. The following isolates of five Trichinella species were used: MFEL/SP/62/GM-1, T. spiralis (Owen, 1835); MPAN/SU/87/T-2, T. nativa Britov, 1971); MCAN/SP76/C-76, T. britovi Pozio, La Rosa, Murrell et Lichtenfelds, 1992), MFEL/US/85/ T-6-FC (Pozio et al. 1992); MCRO/KE/75/T-7, and T. nelsoni Britov, 1971. They are reference strains kept in the Trichinella Reference Centre (Istituto Superiore di Sanitá, Rome).

Experimental hosts. Female BALB/c mice of 8 weeks of age were used. They were bred in our Animal Breeding Unit under controlled light and temperature conditions. Food and water were supplied "ad libitum".

Preparation of larval crude extracts (LCE). L1 muscle larvae were obtained after artificial digestion following the method described by Wakelin and Lloyd (1976). After selection of live larvae by the Baermann method, they were washed 10 times by sedimentation in PBS $\mathrm{pH}$ 7.2-7.4. After washing the settled larvae were placed in an eppendorf tube and sonicated in a Virsonic 5 sonicator for several 10-second pulses at $70 \%$ power. The crude extract was allowed to extract overnight at $4^{\circ} \mathrm{C}$ and then centrifuged at $40,000 \mathrm{~g}$ for 1 hour. The supernatant was collected and the protein content estimated by the Bradford (1976) method. Once aliquoted the samples were stored at $-80^{\circ} \mathrm{C}$.

Preparation of excretory/secretory (ES) products. L1 muscle larvae were recovered and washed as described for LCE preparation. After washing, the settled larvae were suspended in Minimum Essential Medium with Earle's salts (5000 worms $/ \mathrm{ml}$ ), at $\mathrm{pH}$ 7.2-7.4, with added $2 \mathrm{mM} \mathrm{L-}$ glutamine, $10 \mathrm{mM}$ Hepes buffer and antibiotics (50 units/ml penicillin and $50 \mu \mathrm{g} / \mathrm{ml}$ streptomycin) following sterilisation by filtration through a $0.22 \mu \mathrm{m}$ membrane. The larvae were cultured for $24-30$ hours at $37^{\circ} \mathrm{C}$ and $5 \% \mathrm{CO}_{2}$.

After culture the medium containing the ES products was collected by centrifugation at $600 \mathrm{~g}$ and them dialysed against PBS and concentrated by Amicon YM-10 membrane. Protein contents were estimated by the Bradford method (Bradford 1976).

Immunisation. Groups of six animals were prepared per isolate. Each group was immunised with LCE or ES from the corresponding strain emulsified in equal volume of Freund's Complete Adjuvant, at a dose of $500 \mu \mathrm{g} /$ mouse of LCE or 100 $\mu \mathrm{g}$ /mouse of ES, given once by the intramuscular route.

Serum samples. Groups of six mice per strain and immunising antigen were bled weekly for 18-21 weeks, from the retro-orbital venous sinus under ether anaesthesia. Blood samples were allowed to clot and then centrifuged at $900 \mathrm{~g}$ for 15 minutes. Sera samples from the animals of each group were pooled, aliquoted and stored at $-30^{\circ} \mathrm{C}$ until use.

ELISA for the measurement of specific antibodies. Each of the 96-well microtiter plates (Nunc-Immunoplate Maxi Sorp ${ }^{\mathrm{TM}}$ ) was coated with $100 \mu \mathrm{l}$ of LCE or ES products from each isolate at a concentration of $2 \mu \mathrm{g} / \mathrm{ml}$ diluted in $0.1 \mathrm{M}$ carbonate buffer at $\mathrm{pH} 9.6$ and kept overnight at $4^{\circ} \mathrm{C}$. Several wells were kept uncoated as a control for non-specific reactions. After washing three times with $0.05 \%$ PBS-Tween $20,250 \mu \mathrm{l}$ per well of $0.1 \%$ BSA in PBS-Tween were added and the plates then incubated for 1 hour at $37^{\circ} \mathrm{C}$. After washing, $100 \mu \mathrm{l}$ of the $1 / 100$ PBS-Tween $0.1 \%$ BSA diluted sera samples were added in quadruple and the plate was incubated at $37^{\circ} \mathrm{C}$ for 2 hours. As negative controls sera samples taken on the day of infection or immunisation were used. Once the plates were washed, $100 \mu \mathrm{l}$ per well of goat affinity-isolated, horseradish peroxidase-conjugated antibody specific to mouse IgG3 (Caltag Laboratories, San Francisco, $\mathrm{CA}$ ), at the appropriate dilution in PBS-Tween, 0.1\% BSA, were added and incubated for 1 hour at $37^{\circ} \mathrm{C}$. After washing, $100 \mu \mathrm{l}$ per well of substrate (o-phenylenediamine, Sigma) was added at $0.04 \%$ in phosphate-citrate buffer $(\mathrm{pH} 5.0)$ with $0.04 \%$ hydrogen peroxide. The reaction was stopped with 50 $\mu 13 \mathrm{~N}$ sulphuric acid and the plates were read at $492 \mathrm{~nm}$. Results were expressed as optical densities of test sera minus optical densities of control sera values once the values corresponding to non-specific wells were subtracted.

Immunoblot. LCE or ES products from each strain were separated by SDS-PAGE in 5-20\% gradient gels (Laemmli 1970 ) in two sets. One set of separated proteins was stained by Coomasie brilliant blue as a control of native antigens. The other set was used for transference to nitrocellulose paper $(0.2$ $\mu \mathrm{m}$ size pore) in a semi-dry system. The paper was blocked overnight at $4^{\circ} \mathrm{C}$ with $5 \%$ skimmed milk in PBS pH 7.2. The paper was cut into appropriate strips and then incubated with the corresponding sera samples taken from infected or immunised mice on weeks 0,8 and 15 post-infection or immunisation, at $1 / 25$ dilution in $1 \%$ skimmed milk, $1 \%$ Triton X-100 in PBS-Tween 20 and incubated for three hours at $37^{\circ} \mathrm{C}$. After washing three times in PBS-Tween 20 the strips were incubated with goat affinity-isolated, horseradish peroxidase-conjugated antibody specific to mouse IgG3 (Caltag Laboratories, San Francisco, CA), at the appropriate dilution in $1 \%$ skimmed milk, $1 \%$ Triton X-100 in PBSTween 20 for three hours at room temperature. After washing, the bands were developed by adding the substrate $\left(6 \mu 1 \mathrm{H}_{2} \mathrm{O}_{2}\right.$ in $10 \mathrm{ml}$ PBS plus 0.03g 4-chloro-1-naphthol (Sigma) in $10 \mathrm{ml}$ methanol, in dark at room temperature.

Statistics. For statistical study the data belonging to days $10,17,24,38,80$ and 129 were chosen as representative of the whole period of study. The data were submitted to the ANOVA test for the variables species/time. When the interaction was significant $(p<0.05)$ the unifactorial variance analysis was applied to the species variable and when significant $(p<0.05)$ the Duncan`s multiple comparison test was applied (Sokal and Rohlf 1979). 


\section{RESULTS}

Dynamics of the IgG3 response following immunisation of BALB/c mice with LCE from various Trichinella species

The dynamics of IgG3 antibodies are summarised in Fig. 1. Overall high levels of IgG3 were recorded for all species when the sera were tested in ELISA against the homologous corresponding antigens. The highest responses (near 3 O.D.) were recorded in animals immunised with $T$. nelsoni. Antibody levels began to increase sharply by day 31 post-immunisation (p.i.) reaching a maximum by day 66 p.i. and afterwards maintained until the end of the experiment (day 164 p.i.). Similar profiles were recorded for animals immunised with $T$. nativa although the response was slightly delayed with maximum levels reached by day 115 p.i (2.5 O.D.). Immunisations with $T$. spiralis, $T$. britovi and T6 LCE yielded similar IgG3 maximum levels but antibodies appeared earlier in animals immunised with $T$. spiralis (above 0.5 O.D. by day 25 p.i. when the values were at baseline-levels for the remainder).
Dynamics of the IgG3 response following immunisation of $B A L B / c$ mice with ES antigens from various Trichinella species

Following immunisation with ES antigens from various species of Trichinella a significant decrease in IgG3 responses were observed when measured in ELISA against the homologous ES antigens with respect to those recorded in the immunisations with the corresponding LCE (Fig. 2). The earliest response was detected in animals immunised with $T$. britovi with 0.5 O.D. values by day 10 p.i. Antibodies were detected later for the other species although for T. spiralis, T6, and $T$. nelsoni the values increased up to maximum levels similar to those for $T$. britovi between days 38 and 52 p.i., afterwards maintained without significant variation up to the end of the observations (day 164 p.i.). The dynamics of IgG3 following immunisation with $T$. nativa ES antigens varied significantly from those observed in the other species as values remained near basal levels up to day 38 p.i., afterwards reaching the maximum on day 73 , to progressively decrease from then up to the end of the observation (near 0.2 O.D.).
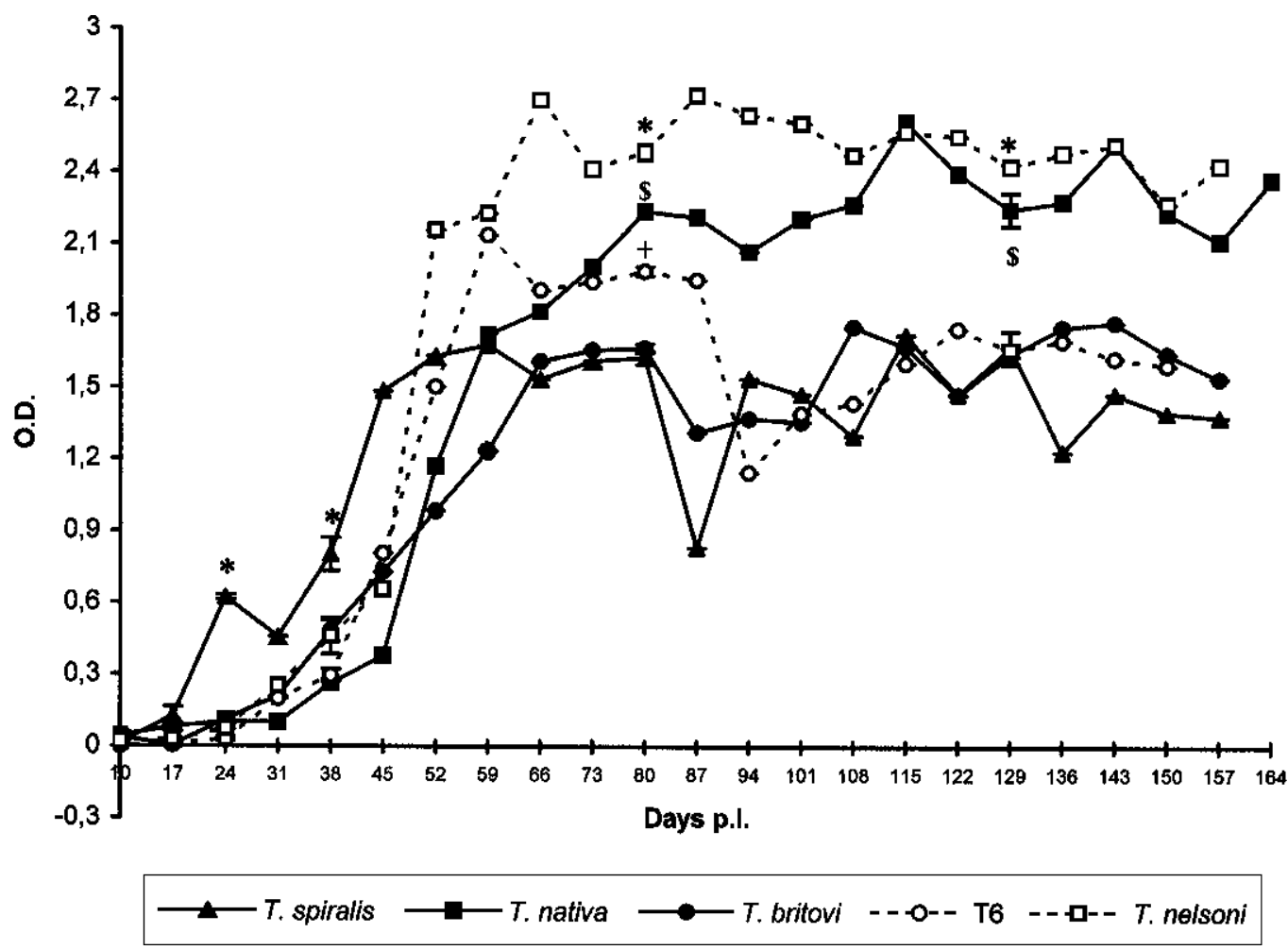

Fig. 1. Dynamics of IgG3 responses following immunisation of BALB/c mice with larval crude extracts (LCE) from isolates of five Trichinella species. Sera samples were taken weekly during a period of 164 days p.i. and tested in ELISA against homologous antigens. Statistical analyses were carried out on data corresponding to days 10, 17, 24, 38, 80 and 129 p.i. as indicated in Materials and Methods. The indications *, $\$$ and + show statistically significant differences at $\mathrm{p}<0.01$. 


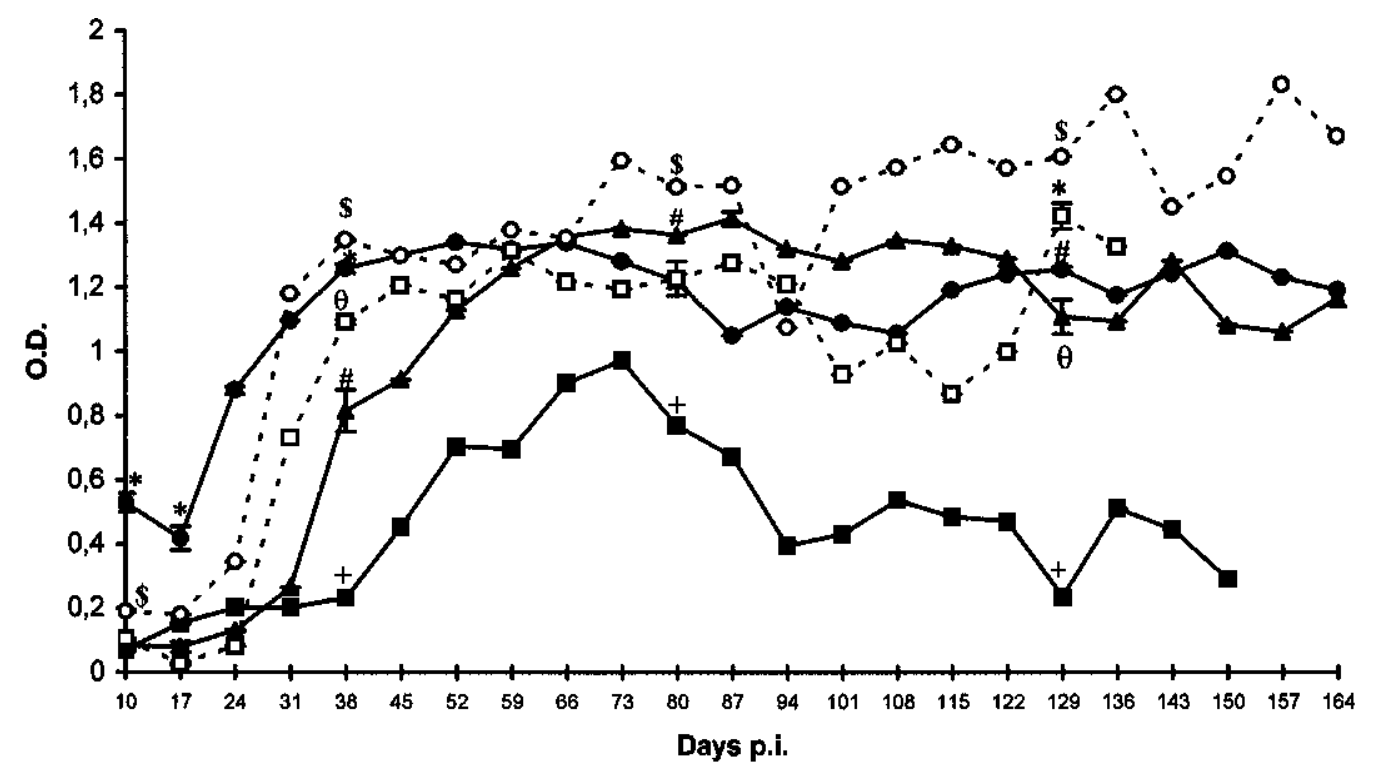

$\longrightarrow$ T. spiralis $\longrightarrow$ T. nativa $\longrightarrow$ T. britovi $--0--$ T6 -- $\longrightarrow$ - T. nelsoni

Fig. 2. Dynamics of IgG3 responses following immunisation of BALB/c mice with excretory-secretory (ES) antigens from isolates of five Trichinella species. Sera samples were taken weekly during a period of 164 days p.i. and tested in ELISA against homologous antigens. Statistical analyses were carried out on data corresponding to days 10,17, 24, 38, 80 and 129 p.i. as indicated in Materials and Methods. The indications $\$, *, \#, \theta$ and + show statistically significant differences at $\mathrm{p}<0.01$.

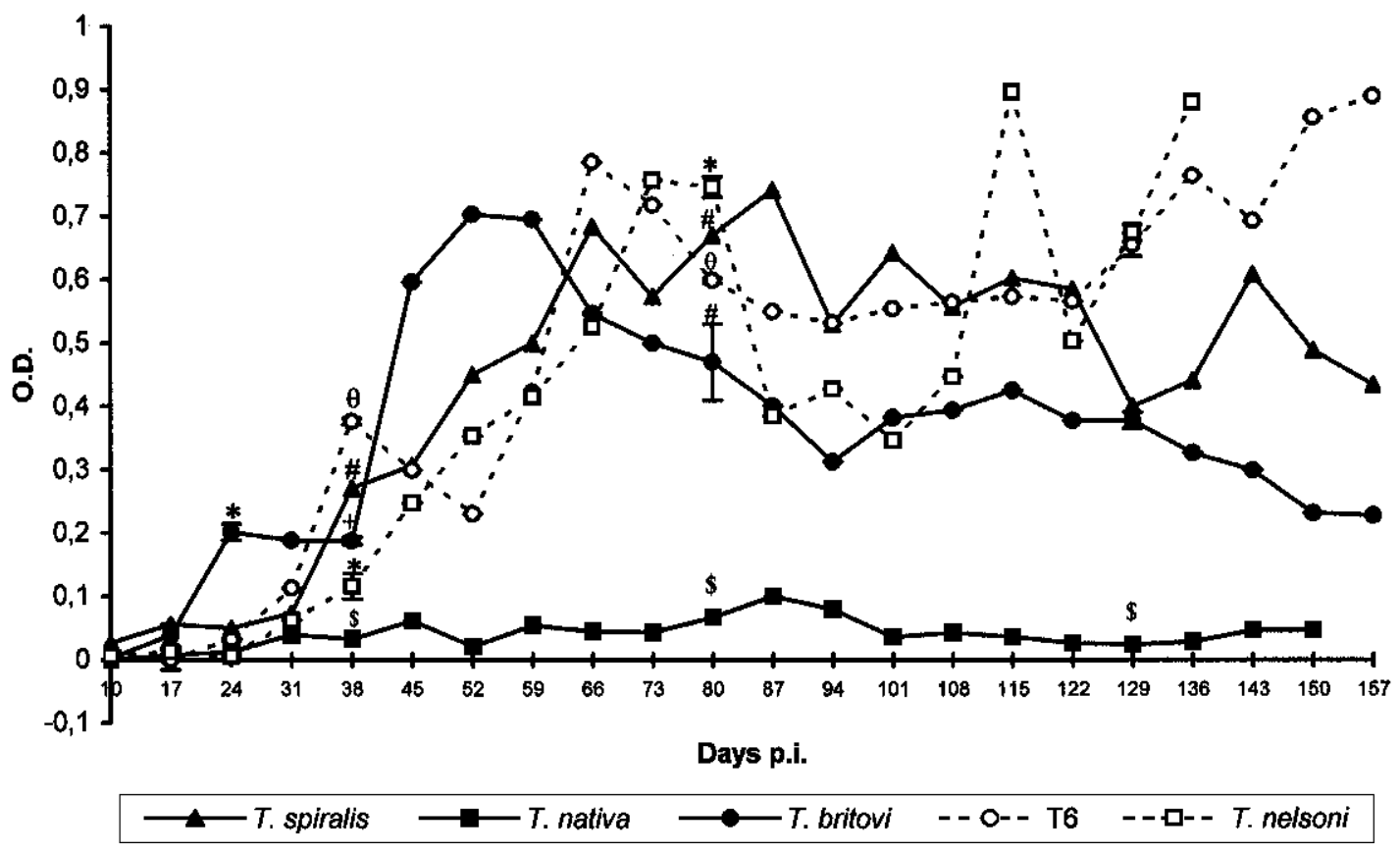

Fig. 3. Dynamics of IgG3 responses following immunisation of BALB/c mice with excretory-secretory (ES) antigens from isolates of five Trichinella species. Sera samples were taken weekly during a period of 164 days p.i. and tested in ELISA against corresponding larval crude extracts (LCE) antigens. Statistical analyses were carried out on data corresponding to days 10, 17, 24, 38, 80 and 129 p.i. as indicated in Materials and Methods. The indications *, \#, $\theta,+$ and $\$$ show statistically significant differences at $\mathrm{p}<0.01$. 
a

b

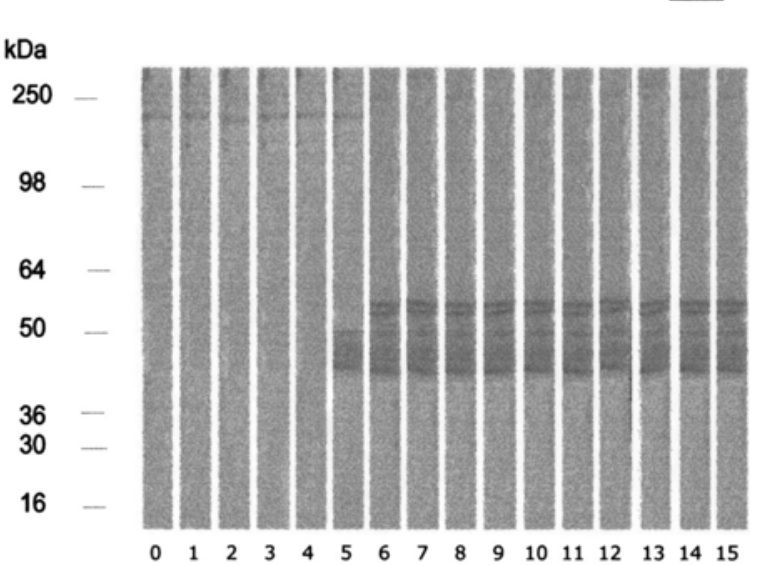

$\mathrm{kDa}$

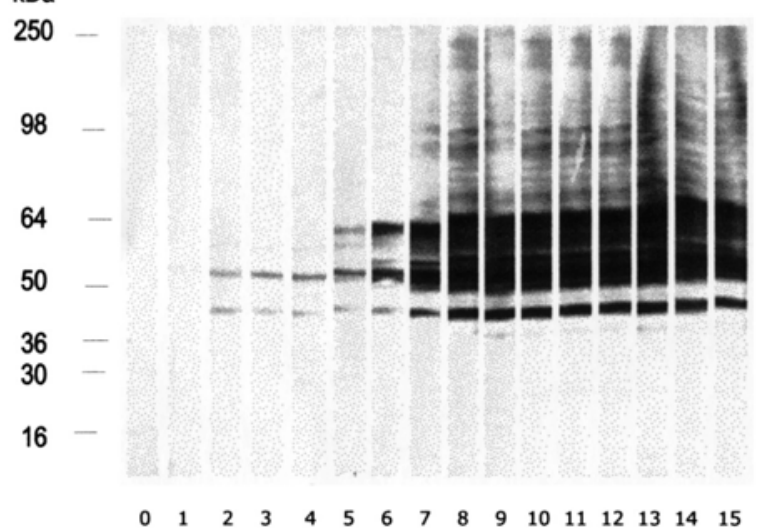

C

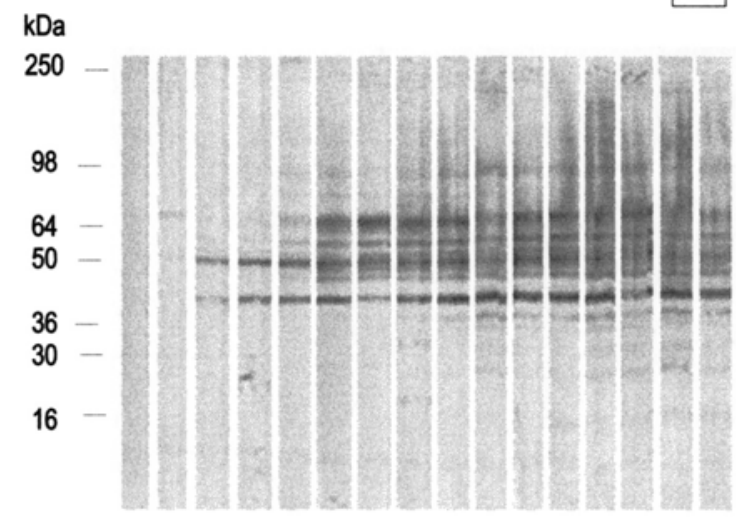

$\mathrm{kDa}$

250

98

64

$50-$

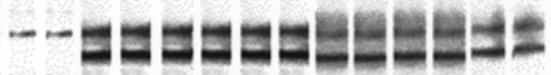

$36-$

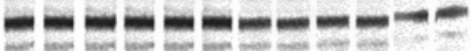

30

16

$\begin{array}{llllllllllllllll}0 & 1 & 2 & 3 & 4 & 5 & 6 & 7 & 8 & 9 & 10 & 11 & 12 & 13 & 14 & 15\end{array}$

$\begin{array}{llllllllllllllll}0 & 1 & 2 & 3 & 4 & 5 & 6 & 7 & 8 & 9 & 10 & 11 & 12 & 13 & 14 & 15\end{array}$

$\mathbf{e}$

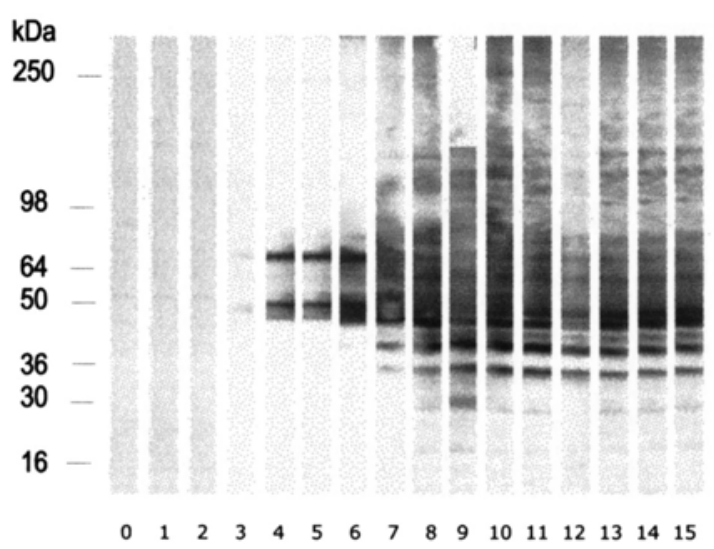

Fig. 4. Antigen recognition by $\operatorname{IgG} 3$ following immunisation of BALB/c mice with larval crude extracts (LCE) from isolates of five Trichinella species. Sera samples were assayed for 15 weeks after immunisation by western-blot using homologous antigens. The numbers below the lines indicate weeks p.i. Lanes numbered 0 correspond to pre-immunisation serum samples. aT. spiralis; $\mathbf{b}-$ T. nativa; $\mathbf{c}-$ T. britovi; $\mathbf{d}-\mathrm{T} 6 ; \mathbf{e}-$ T. nelsoni. 
a

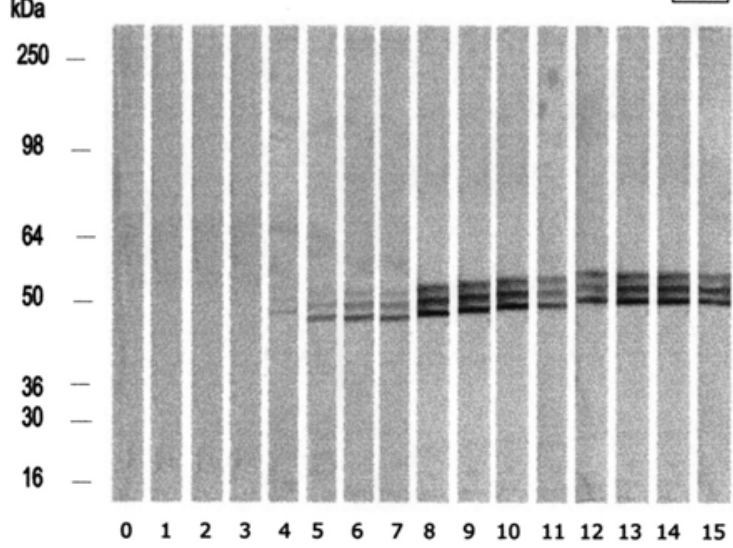

b

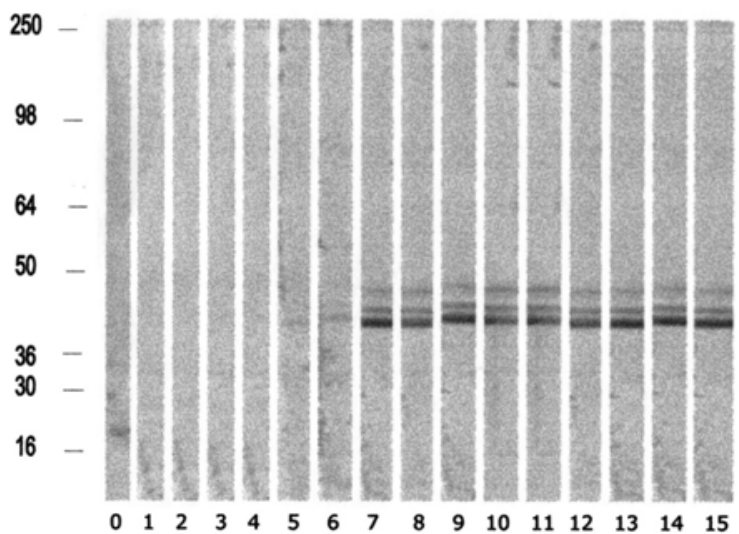

d

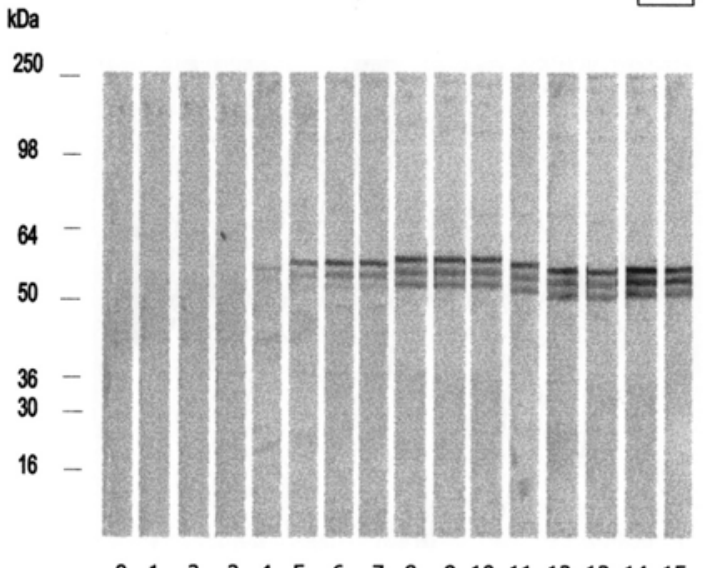

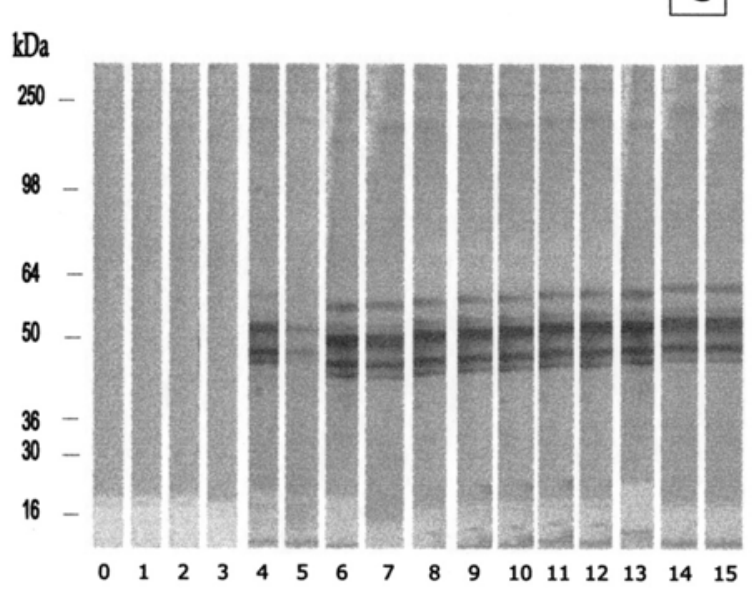

e

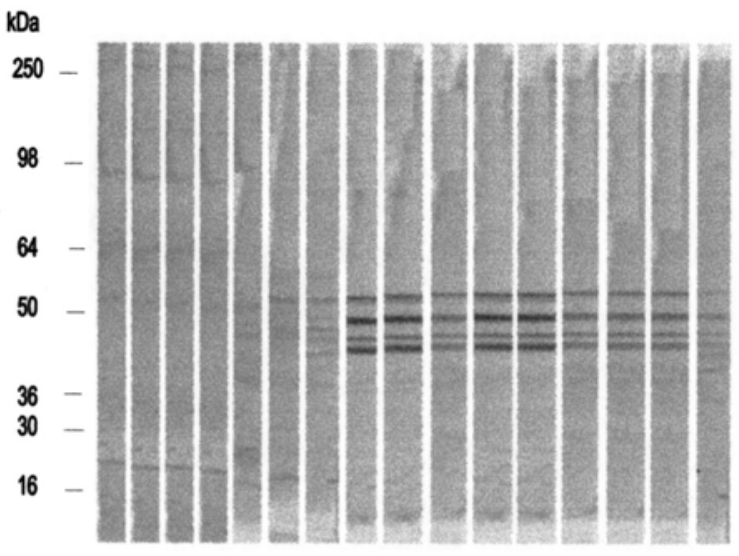

$\begin{array}{llllllllllllllll}0 & 1 & 2 & 3 & 4 & 5 & 6 & 7 & 8 & 9 & 10 & 11 & 12 & 13 & 14 & 15\end{array}$

Fig. 5. Antigen recognition by IgG3 following immunisation of BALB/c mice with excretory-secretory (ES) antigens from isolates of five Trichinella species. Sera samples were assayed for 16 weeks after immunisation by western-blot with homologous antigens. The numbers below the lines indicate weeks p.i. a - T. spiralis; $\mathbf{b}-T$. nativa; $\mathbf{c}-$ T. britovi; $\mathbf{d}-\mathrm{T} 6 ; \mathbf{e}-T$. nelsoni. 
When the sera from animals immunised with ES antigens were tested in ELISA against the corresponding LCE, the IgG3 responses again significantly decreased in relation those measured against the homologous ES antigens (Fig. 3). In all cases values remained below 1.0 O.D. with almost no response for animals immunised with $T$. nativa. For those immunised with $T$. britovi the maximum $\operatorname{IgG} 3$ response $(0.7$ O.D.) was recorded by day 52 p.i. and from then the values progressively dropped up to the end of the observation (near 0.2 O.D. on day 157 p.i.) The dynamics observed for animals immunised with $T$. spiralis, T. nelsoni and T6 were similar with maximum values reached between days 65 and 73 p.i. and afterwards maintained with significant fluctuations up to the end of the observation.

\section{Antigen recognition profiles following immunisation of $B A L B / c$ mice with LCE or ES antigens from various Trichinella species}

IgG3 antigen recognition in western-blot with LCE by sera from animals immunised with homologous antigens is shown in Fig. 4a-e. Recognition profiles were quite complex with high reactivity between 45 and $64 \mathrm{kDa}$ in animals immunised with $T$. nativa, $T$. britovi and T. nelsoni LCE. Two bands of about 40 and $53 \mathrm{kDa}$ respectively were recognised in animals immunised with $T$. nativa and $T$. britovi LCE from week $2^{\text {nd }}$ onwards with the number of bands increasing from week $5^{\text {th }}$. IgG3 recognition profiles in animals immunised with LCE from $T$. nelsoni were quite different from those mentioned above as new bands of about 48 and $64 \mathrm{kDa}$ were present from week $3^{\text {rd }}$ to $6^{\text {th }}$ followed by three major bands in the range of 35-45 $\mathrm{kDa}$ that were apparent throughout the observation (week $15^{\text {th }}$ p.i.). Less complex IgG3 recognition profiles from the former species were observed following immunisation with $T$. spiralis and T6 although the patterns were quite different from each other. In animals immunised with $T$. spiralis LCE a few faint bands between 45 and $55 \mathrm{kDa}$ were apparent from week 6 p.i. and were maintained up to the end of the experiment whereas in those immunised by T6 LCE a clear band of about $50 \mathrm{kDa}$ was visible from week $2^{\text {nd }}$ and three new prominent bands of about 32,35 and $45 \mathrm{kDa}$ were observed from week $4^{\text {th }}$ onwards.

Following immunisation with ES antigens from different species the IgG3 recognition profiles as measured in western-blot with the homologous antigens were quite simple (Fig. 5a-e). The patterns were almost identical for animals immunised with $T$. spiralis, $T$. nativa and T6 ES antigens where three major bands between 45 and $50 \mathrm{kDa}$ were present from weeks 4-5 p.i. onwards. In animals immunised with $T$. britovi and T. nelsoni ES antigens an additional band of about 40$43 \mathrm{kDa}$ was also present from week 6 p.i. onwards.

\section{DISCUSSION}

The results presented here clearly show the influence of the species and the type and source of antigen used for immunisation on the $\operatorname{IgG} 3$ antibody subclass response. The highest IgG3 antibody response was induced by somatic antigens from Trichinella nelsoni and $T$. nativa. Very high levels of $\operatorname{IgG} 3$ were also induced by somatic products from $T$. spiralis, $T$. britovi and from $\mathrm{T} 6$ with the earliest response observed in $T$. spiralis (Fig. 1). These variations were confirmed in the recognition profiles obtained by western-blot with homologous antigens particularly at the highly dense reactive areas (between 45 and $64 \mathrm{kDa}$ ) (Fig. 4). These highly dense reactive areas of Trichinella larval antigens have been shown to contain glycoproteins involved in important functions of the parasite such as infectivity (McVay et al. 1998) and nurse cell development (Vassilatis et al. 1992, 1996).

The IgG3 response was significantly lower following immunisation with ES antigens in all species especially in animals immunised with T. nativa (Figs. 2, 3). This was consistent with the simplified recognition profiles observed in western-blot with the homologous antigens where only three main bands appeared for most species thus suggesting a lower content of IgG3 epitopes in ES antigens in comparison to somatic LCE (Fig. 5). Likewise a dramatic reduction in $\mathrm{IgG} 3$ responses was shown in all species when the sera from animals immunised with ES antigens were tested in ELISA against homologous LCE (Fig. 3) although this reduction was lower when the same sera were tested against the homologous ES antigen (Fig. 1). The apparent higher IgG3 epitopes in the LCE could simply be due to the different amount of antigens used in immunisation assays as about five times more LCE than ES was used. This patterns of immunisation was chosen for comparative purposes as much of the ES antigens constitutes also a small part of the LCE content. Nevertheless it does not seem to be the case as IgG3 response against LCE should not be markedly higher than that against ES antigens if the IgG3 inducing epitopes were mainly present in the later. Contrarily, despite the higher IgG3 responses in animals immunised with ES when tested in ELISA with homologous antigens (Fig. 2), these responses still clearly remained under those obtained when the animals were immunised with the LCE (Fig. 1).

The protein profiles of ES and LCE from the different isolates were assessed by SDS-PAGE analysis with no major variations among the species (data not shown). Nevertheless significant variation was observed in both the dynamics and the antigen recognition profiles by IgG3 generated against the LCE from different species suggesting the presence of different 
IgG3 epitopes. This is consistent with the antigenic variation among Trichinella species evidenced in previous studies (Bolas-Fernández and Wakelin 1990, 1992, Goyal and Wakelin 1993, Saito et al. 1994, Boireau et al. 1997, Goyal et al. 1997) although little is known on the chemical structure and biological functions of these species- and isolate-variant antigens.

For comparative purposes the experiments here described were designed as immunisation- rather than infection-based assays owing to the great variation in infectivity shown by the different species as assessed in complementary experiments (data not shown). Therefore comparison of our results with those from previous authors working only with $T$. spiralis, and mainly at the early stages of infection, is not applicable as the amount of antigens released and their dynamics in infection and in immunisation are likely to be quite different.

IgG3 response against carbohydrate-containing ES antigens (Group II of Denkers et al. 1990b) was found to be very low when tested on day 28 after injection of these antigens in AKR/J mice with the major response being IgG1 mediated. These findings seem to correlate with our results obtained in a different strain of mice where values were significantly lower than those obtained with LCE. In addition we corroborate that IgG3 responses against ES products did not increase with time whereas those against somatic (LCE) products were progressively increasing up to very high levels reached between days 59 and 66 p.i. afterwards maintained in all species (Fig. 1). Therefore our results suggest that despite the presence of relevant carbohydrates in ES antigens of Trichinella (TSL1) as previously reported these antigens do not seem to be the main targets for Ig3 antibodies. Glycoproteins are also abundant components of the somatic antigens (LCE) (Parkhouse and Ortega-Pierres 1984) and some carbohydrates present in ES antigens were also identified in somatic products (Wisnewski et al. 1993). Whether these or other carbohydrates as well as other biomolecules of the LCE play an important role in triggering IgG3 responses deserves further investigation.

The precise characterisation of IgG3 epitopes by controlled deglycosylation protocols combined with competitive immunoassay with monoclonal antibodies against particular carbohydrates together with the assessment of the dynamics of $\operatorname{IgG} 3$ in equivalent infections by different species is currently being investigated.

\section{REFERENCES}

ALMOND N.M., PARKHOUSE R.M.E. 1986: Immunoglobulin class specific responses to biochemically defined antigens of Trichinella spiralis. Parasite Immunol. 8: 391406.

APPLETON J.A., McGREGOR D.D. 1984: Rapid expulsion of Trichinella spiralis in suckling rats. Science 226: 7072.

APPLETON J.A., McGREGOR D.D. 1987: Characterization of the immune mediator of rapid expulsion of Trichinella spiralis in suckling rats. Immunology 62: 477-484.

BELL R.G. 1992a: Variation in responsiveness to Trichinella spiralis infection in inbred rat strains. Parasitology 105: 125-130.

BELL R.G. 1992b: Trichinella spiralis: evidence that mice do not express rapid expulsion. Exp. Parasitol. 74: 417-430.

BOIREAU P., VAYSSIER M., FABIEN J.F., PERRET C., CALAMEL M., SOULE C. 1997: Characterisation of eleven antigenic groups in Trichinella genus and identification of stage and species markers. Parasitology 115: 641-651.

BOLAS-FERNANDEZ F., WAKELIN D. 1990: Infectivity, antigenicity and host responses to isolates of the genus Trichinella. Parasitology 100: 491-497.

BOLAS-FERNANDEZ F., WAKELIN D. 1992: Immunization against geographical isolates of Trichinella spiralis in mice. Int. J. Parasitol. 22: 773-781.

BRADFORD M. 1976: A rapid and sensitive method for quantitation of microgram quantities of protein utilizing the principle of protein-dye binding. Anal. Biochem. 72: 248-252.
BRITOV V.A., BOEV S.N. 1972: Taxonomic rank of various strains of Trichinella and their circulation in nature. Vestn. Akad. Nauk SSSR 28: 27-32.

CRANDALL R.B., CRANDALL C.A. 1972: Trichinella spiralis: immunological response to infection in mice. Exp. Parasitol. 31: 378-398.

DENKERS E.Y., HAYES C.E., WASSON D.L. 1991: Trichinella spiralis: influence of an immunodominant, carbohydrate-associated determinant on the host antibody response repertoire. Exp. Parasitol. 72: 403-410.

DENKERS E.Y., WASSON D.L., HAYES C.E. 1990a: Characterisation of Trichinella spiralis antigens sharing an immunodominant, carbohydrate-associated determinant distinct from phosphorylcholine. Mol. Biochem. Parasitol. 41: 241-250.

DENKERS E.Y., WASSON D.L., KRCO C.J., HAYES C.E. 1990b: The mouse antibody response to Trichinella spiralis defines a single, immunodominant epitope shared by multiple antigens. J. Immunol. 144: 1352-1360.

DESPOMMIER D.D. 1975: Adaptative changes in muscle fibers infected with Trichinella spiralis. Am. J. Pathol. 78: 477-496.

DRABEK D., RAGUZ S., DE WIT T.P., DINGJAN G.M., SAVELKOUL H.F., GROSVELD F., HENDRIKS R.W. 1997: Correction of the X-linked immunodeficiency phenotype by transgenic expression of human Bruton tyrosine kinase under the control of the class II major histocompatibility complex Ea locus control region. Proc. Natl. Acad. Sci. U.S.A. 94: 610-615. 
DUNNE D.W. 1990: Schistosoma carbohydrates. Parasitol. Today 6: 45-48.

ELLIS L.A., REASON A.J., MORRIS H.R., DELL A., IGLESIAS R., UBEIRA F., APPLETON J.A. 1994: Glycans as targets for monoclonal antibodies that protect rats against Trichinella spiralis. Glycobiology 4: 585-592.

FERGUSON M.A.J., HOMANS S.W., DWEK R.A., RADEMACHER T.W. 1988: Glycosylphosphatidyl-inositol moiety that anchors Trypanosoma brucei variant surface antigen to the membrane. Science 239: 753-759.

GOYAL P.K., BOLAS-FERNANDEZ F., WAKELIN D. 1997: Immunization of mice against Trichinella spiralis and $T$. britovi using excretory and secretory antigens. J. Helminthol. 71: 109-112.

GOYAL P.K., WAKELIN D. 1993: Vaccination against Trichinella spiralis in mice using antigens from different isolates. Parasitology 107: 311-317.

GREENSPAN N.S., COOPER L.J.N. 1992: Intermolecular cooperativity: a clue to why mice have IgG3? Immunol. Today 13: 164-168.

LAEMMLI U.K. 1970: Cleavage of structural proteins during the assembly of the head of bacteriophage T4. Nature (Lond.) 277: 680-685.

LJUNGSTROM I., HAMMARSTROM L., KOCIECKA W., SMITH C.I. 1988: The sequential appearance of $\mathrm{IgG}$ subclasses and IgE during the course of Trichinella spiralis infection. Clin. Exp. Immunol. 74: 230-235.

McVAY C.S., TSUNG A., APPLETON J. 1998: Participation of parasite surface glycoproteins in antibody-mediated protection of epithelial cells against Trichinella spiralis. Infect. Immun. 66: 1941-1945.

OTTESEN E.A. SMITH T.K., KIRKPATRICK C.H. 1975: Immune response to Trichinella spiralis in the rat. I. Development of cellular and humoral response during chronic infection. Int. Arch. Allergy Appl. Immunol. 49: 396-410.

PARKHOUSE R.M.E., ORTEGA-PIERRES G. 1984: Stagespecific antigens of Trichinella spiralis. Parasitology 88: 623-630.

POZIO E., LA ROSA G., MURRELL K.D., LICHTENFELDS J.R. 1992: Taxonomic revision of the genus Trichinella. J. Parasitol. 78: 654-659.

ROBINSON K., BELLAMY T., WAKELIN D. 1994: Vaccination against the nematode Trichinella spiralis in high- and low-responder mice. Effects of different adjuvants upon protective immunity and immune responsiveness. Immunology 82: 261-267.

ROBINSON K., BELLAMY T., WAKELIN D. 1995a: Immunity to Trichinella spiralis transferred by serum from vaccinated mice not protected by immunization. Parasite Immunol. 17: 85-90.
ROBINSON K., BELLAMY T., WAKELIN D. 1995b: Immune response profiles in vaccinated and nonvaccinated high- and low-responder mice during infection with the intestinal nematode Trichinella spiralis. Parasitology 110: 71-78.

SAITO S., ROJEKITTIKHUN W., GAO P., WATANABE T., YAMASHITA T., SENDO F. 1994: Monoclonal antibodies to Trichinella spiralis muscle larvae that mimic serum antibody from trichinellosis mice and discriminate various isolates of the worm. Jpn. J. Parasitol. 43: 265273.

SNAPPER C.M., McINTYRE T.M., MANDLER R., PECANHA L.M.T., FINKELMAN F.D., MOND J.J. 1992: Induction of IgG3 secretion by interferon- $\gamma$ : a model for $\mathrm{T}$ cell-independent class switching in response to Tcell independent Type 2 antigens. J. Exp. Med. 175: 13671371.

SOKAL R.R., ROHLF F.J. 1979: Biometria. Principios y Métodos Estadísticos en la Investigación Biológica. H. Blume Ed., Madrid, Spain, 832 pp.

TAKAHASHI Y., MIZUNO N., UNO T., AISAKA A., ARAKI T. 1990: A spectrum antibody response with time after Trichinella spiralis infection in rats. J. Parasitol. 76: 230-239.

VASSILATIS D.K., DESPOMMIER D.D., MISEK D.E., POLVERE R.I., GOLD A.M., Van der PLOEG L.H.T. 1992: Analysis of a 43-kDa glycoprotein from the intracellular parasite nematode Trichinella spiralis. J. Biol. Chem. 267: 18459-18465.

VASSILATIS D.K., POLVERE R.I., DESPOMMIER D.D., GOLD A.M., Van der PLOEG L.H.T. 1996: Developmental expression of a $43-\mathrm{kDa}$ secreted glyco-protein from Trichinella spiralis. Mol. Biochem. Parasitol. 78: 13-23.

WAKELIN D. 1993: Trichinella spiralis: immunity, ecology, and evolution. J. Parasitol. 79: 488-494.

WAKELIN D., DENHAM D. 1983: The immune response. In: W.C. Campbell (Ed.), Trichinella and Trichinellosis. Plenum Press, New York, pp. 265-308.

WAKELIN D., LLOYD M. 1976: Immunity to primary and challenge infections of Trichinella spiralis: a reexamination of conventional parameters. Parasitology 72 : 173-182.

WISNEWSKI N., McNEIL M., GRIEVE R.B., WASSON D.L. 1993: Characterization of novel fucosyl- and tyvelosyl-containing glycoconjugates from Trichinella spiralis muscle stage larvae. Mol. Biochem. Parasitol. 61: 25-36.

ZAKROFF S.G., BECK L., PLATZER E.G., SPIEGELBERG H.L. 1989: The IgE and IgG subclass responses of mice to four helminth parasites. Cell. Immunol. 119: 193-201. 